to the main events and ideas in the correspondence; without it, it would be difficult to keep in mind the main themes when reading the chronological series of letters. There is also an explanation of the editors' triage of the voluminous correspondence: some letters are known but are inaccessible now, and the editors relegated other, less significant, letters to reference in a calendar at the end of the volume. And although the correspondence is presented only in the original language, mostly German, happily there exists a separately published English translation, provided by Ann and Klaus

Hentschel (Princeton University Press, 2005).

Many of the most intimate letters in volume 9 are exchanges between Einstein and Max Born and his wife Hedwig. Here, Einstein can truly relax and share the good and the sad in his life, his scientific, social, musical and personal thoughts. Max Born, whose Nobel prize for his work in quantum mechanics was delayed until 1954, contributed to a wide spectrum of fields, including relativity, optics, crystal physics, epistemology, the theory of liquids and arms control. Max and Hedwig, who was a delightful companion and correspondent, left Germany for Edinburgh after Max was driven out from Göttingen in 1933. His son, Gustav, tells that his father had taken seriously Einstein's advice to leave immediately, "thus helping to save the family".

The 117 surviving letters between the Borns and Einstein from 1916 to 1955 were published as a book in German in 1969, with an introduction by Werner Heisenberg, at one time Born's assistant. It had a foreword by Bertrand Russell, who succinctly summarized what that book showed in its essence: "In an age of mediocrity and moral pygmies, their lives shine with an intense beauty. Something of this is reflected in their correspondence, and the world is richer for its publication.” For most of the letters, Max Born provided perceptive editorial comments, explaining the circumstances of the time in which the letters were written.

An English translation of the book appeared in 1971, but has been long out of print. The new English-language edition of The Born-Einstein Letters 1916-1955 issued by Nature's publisher Macmillan as part of its new science imprint - is essentially unchanged from the earlier version, but greatly benefits from an extensive preface by Buchwald and the physicist Kip Thorne. To quote from the preface: "The letters themselves constitute one of the most vivid and valuable testimonies to the development of modern science. They also tell us much about the personal hardships that Einstein and Born overcame during two world wars, the vagaries of academic life, the daily grind of administrative work, the steadfastness and frailty of human relationships."

Perhaps the most famous of these letters deal with the fundamental difference between these two good friends, with Born upholding what came to be the Copenhagen interpretation of quantum mechanics, according to which the foundations of physics are laws of statistical nature. Einstein responded in 1926: "Quantum mechanics is certainly imposing. But an inner voice tells me that it is not yet the real thing. The theory says a lot. But it does not really bring us any closer to the secrets of the 'old one'. I, at any rate, am convinced that $\mathrm{He}$ is not playing at dice."

This judgement, Born records, was for him "a hard blow”, separating Einstein from the younger physicists of which Born, though only a few years younger than Einstein, considered himself part. But the friendship survived, not least by the intervention of Wolfgang Pauli, who cleared up a misunderstanding between Born and Einstein. The exchange of letters continued, testifying to their constant interests in developments ranging from atomic physics to cosmic rays, from quantum mechanics to stellar spectra, and of course relativity (the new 'ether drift' experiments, gravitational red shift, gravitational light deflection and gravitational waves).

But we hear also about the pair's intervention in humanitarian causes, the turmoil in politics throughout Europe after the First World War, programmes to help refugee scientists, and the devastating events of the Second World War. The new preface also contains valuable brief accounts of the way that physics, after the death of these two great minds, continued along lines they had pursued, showing in some detail how experimental and theoretical work in the past few decades has confirmed with great precision some of their daring speculations.

In short, these two related volumes act as a kind of microscope through which to view a turbulent period in the twentieth century.

Gerald Holton is Mallinckrodt research professor of physics and research professor of the history of science, Department of Physics, Harvard

University, Cambridge, Massachusetts 02138, USA.

\section{Relativity revisited}

The Meaning of Relativity (5th edn) by Albert Einstein, with an introduction by Brian Greene

Princeton University Press: 2004. 192 pp.

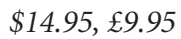

\section{Special Relativity: A First}

Encounter

by Domenico Giulini

Oxford University Press: 2005. 160 pp.

£14.99, \$24.95

Einstein 1905: The Standard

of Greatness

by John S. Rigden

Harvard University Press: 2005. 192 pp.

$\$ 21.95, £ 14.95$

\section{Werner Israel}

What, another three books on Einstein? At the last count on www.amazon.com there were 498 currently in print, and the proliferation of titles such as The Private Albert Einstein, Einstein in Love and Einstein's Daughter should ensure that no corner of his life is left untouched.

As a refreshing change, The Meaning of Relativity, Special Relativity and Einstein 1905 deal exclusively with science. All three are valuable additions to the Einstein canon. The Meaning of Relativity, the master's own presentation based on lectures given at Princeton University in 1921, reappears in a reprinting of the final (1953) edition, which included as an appendix his parting thoughts on his last abortive bid to unify the gravitational and electromagnetic forces. This was in fact a revival, with modifications, of his earliest attempt, begun in 1925 but soon abandoned because, as he admitted in 1927: "As a result of numerous failures, I have come to the conclusion that this road does not lead us closer to the truth." It is curious that none of his later works mentions this early attempt. Not too much should be made of this; Einstein was always sparing with references (this entire book has just one). Yet one cannot help wondering: could it have slipped his mind that he had been down this path before?

Brian Greene's easy-to-read 24-page introduction touches on several developments since Einstein's time. One of these is superstring theory, which carries forward Einstein's quest for unification. Another is the recent discovery that the cosmic expansion is accelerating, with its strong implication that Einstein's self-styled "greatest blunder" — the cosmological constant — was perhaps not such a dumb idea after all.

Giulini's book Special Relativity has a narrower focus, concentrating exclusively on Einstein's special theory of relativity. It is particularly strong on experimental tests and ramifications of the theory, and on the evolution of relativistic ideas, from Galileo and Newton, through the nineteenth-century 


\section{The great portrait mystery}

\section{A disputed portrait of Robert Hooke may in fact show a contemporary.}

\section{Philip Ball}

At the tricentenary of Robert Hooke's death two years ago, no one knew what he looked like. Despite Hooke's reputation as one of the principal architects of the scientific revolution, there were no known surviving portraits of him - an outcome, it was rumoured, of his enmity with Isaac Newton, who did all he could to erase Hooke's image after his death.

But in 2003, historian Lisa Jardine ruffled academic feathers by boldly claiming to have discovered a portrait of Hooke, which featured on the cover of her biography The Curious Life of Robert Hooke (HarperCollins, 2003). This painting has resided for more than a century in the Natural History Museum in London, where it was taken to be a portrait of the British naturalist John Ray (1627-1705) painted by the seventeenthcentury artist Mary Beale. The painting was bequeathed as such to the museum in 1787 after the death of its former owner, the botanist William Watson.

Jardine argued that the visage looks nothing like other portraits of Ray, and that the features instead match some contemporary descriptions of Hooke, who was said to have bulging grey eyes and curly brown hair and to be of emaciated appearance. Others have found this evidence not only slender but also unconvincing: the face is certainly unusual, but does it really correspond in any regard to these accounts?

Now William Jensen, a specialist in the history of chemistry at the University of Cincinnati, has an alternative proposal. He points out in Ambix (51, 263; 2004) that the portrait can be superimposed remarkably well onto an engraving of another influential seventeenth-century scientist, the Flemish chemist and physician Jan Baptista van Helmont (1579-1644). The engraving appears in the 1648 edition of van Helmont's great work

aether theorists, and up to A. A. Michelson, Edward Morley, George FitzGerald and Hendrik Lorentz.

Have Lorentz and Henri Poincaré received less than their due in this great conceptual revolution? I think Giulini puts the case fairly: "In retrospect, special relativity seems palpably close in 1905, after all the preliminary works of Voigt, Hertz, FitzGerald, Lorentz, Larmor and Poincaré. But apparently it needed an unprejudiced newcomer to take the final step."

The mathematical demands of these two

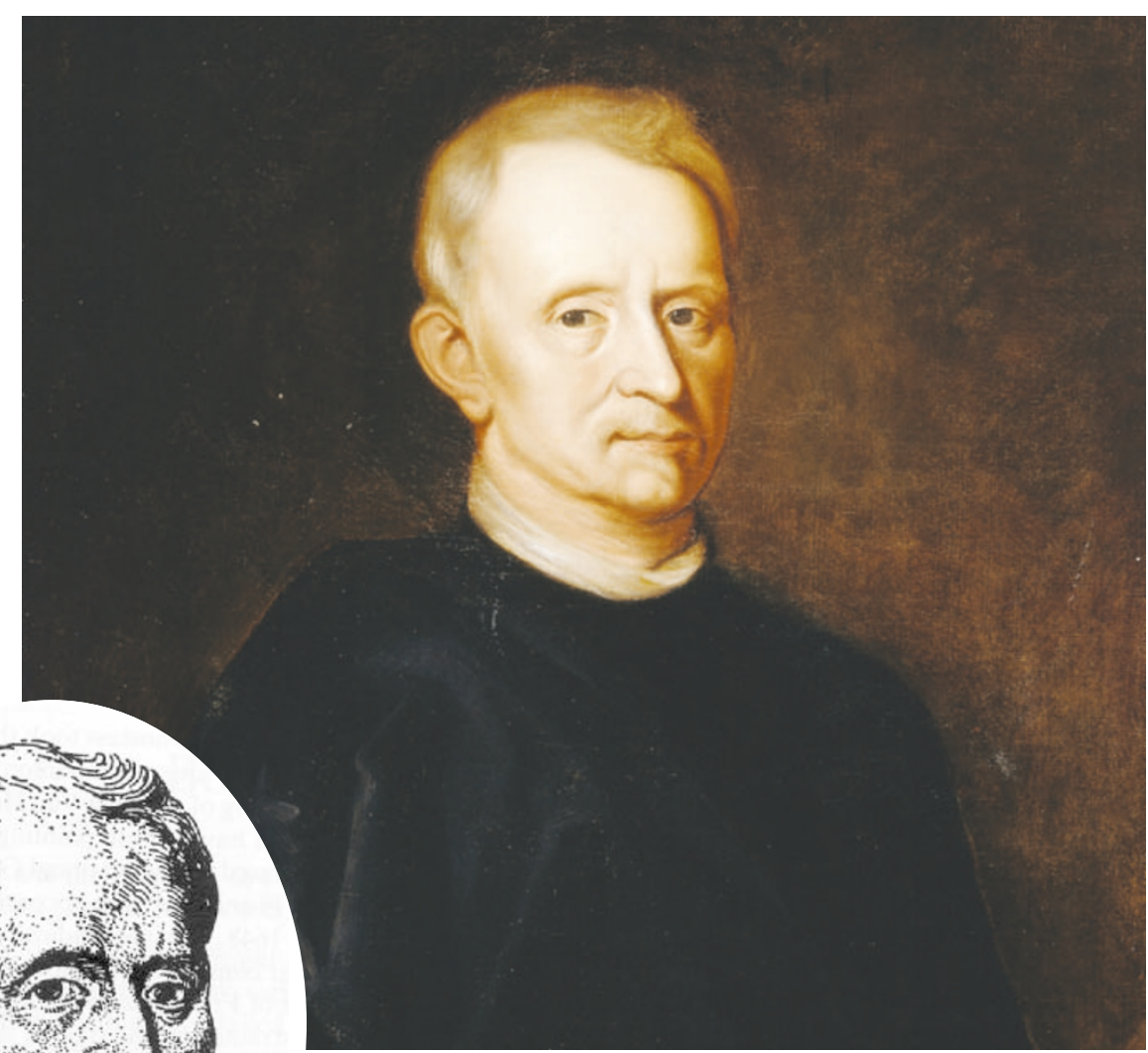

Getting the brush-off: the above painting, thought to be of Robert Hooke, may have been based on an engraving of Jan Baptista van Helmont.

Ortus medicinae, pub-

lished posthumously by his son Franciscus Mercurius van Helmont (whose likeness is inserted behind his father's on the same page). Van Helmont's writings were never published in his lifetime because he was persecuted as a heretic by the Spanish Inquisition and forced to live under house arrest in Vilvoorde, near Brussels, until his death.

Particularly telling is the wispy moustache and underlip hair in the 1648 work, which is reproduced in the portrait thought to be of Ray. There is no record of Hooke having sported such facial hair. Hooke was only nine years old when van
Helmont died, so there seems to be no possibility of the reverse confusion.

So where did the 'Ray' painting come from? Jensen says that Franciscus van Helmont had his own portrait made while he resided in England during the 1670s, and might have commissioned a picture of his father at the same time, based on the earlier engraving. But then who was the artist? And why did Watson, a hundred years later, have the false impression that he owned a painting of Ray by Mary Beale?

The haunting image clearly still holds mysteries. But the face of poor Robert Hooke may have vanished once more from history.

Philip Ball is a consultant editor for Nature.

volumes are not heavy (Giulini uses nothing beyond high-school algebra), but they do require close attention from the reader. In a lighter vein is John Rigden's enjoyable contribution, Einstein 1905. This is a month-bymonth chronicle of 1905, Einstein's annus mirabilis, in which appeared in quick succession his four epoch-making papers on the photon hypothesis, brownian motion, special relativity and $E=m c^{2}$. Rigden explains the underlying ideas in clear, elegant, nonmathematical prose. Amusingly, of all of Einstein's 1905 works, the one most cited today is none of the above (they are scarcely cited at all), but his $\mathrm{PhD}$ thesis on the determination of molecular dimensions. This is because the methods he used for it have been widely applied to such problems as the motion of sand particles in cement mixes and of aerosol particles in clouds. As Rigden remarks: "When a paper is so important that it could be cited in almost every paper, it is cited in almost no paper".

Werner Israel is in the Department of Physics,

University of Victoria, Victoria, British Columbia, V8W 3P6, Canada. 